\title{
Damnificados del sistema
}

Cuando ocurre un desastre, como el reciente terremoto, hay lugar para muchas acciones y cada cual actúa desde su propia perspectiva, visión o actitud ante la vida y las cosas, es decir, cada persona, a su manera, sufre, maldice, ayuda, agradece a Dios, analiza, denuncia, se solidariza o se indigna. No falta, inclusive, quien simplemente llame a nuestro país como un error geológico e histórico.

Lo cierto es que en circunstancias como las actuales, las realidades de una sociedad como la nuestra se hacen más evidentes: las carencias, el oportunismo, las ganguerías, la solidaridad, la hermandad, la generosidad, la desorganización, la demagogia, elc. Todas las miserias y las bondades humanas se nos hacen presentes, lo cual podria parecer como normal, pero también se ponen de manifiesto las deficiencias del sistema socioeconómico y del régimen político.

Ciertamente se puede tomar cualquier tópico y quienes sentimos la necesidad, podemos escribir unas cuantas cuartillas, según se nos presente la realidad. Así, por ejemplo, podemos hablar del Comité de Emergencia Nacional y de su inoperancia; del palabrerío hueco de su presidente; de la rabieta del director de El Diario de Hoy contra Mauricio Funes, del Canal 12; del oportunismo de los partidos políticos; de los esfuerzos del pueblo queriendo salvar al pueblo; de las denuncias de los alcaldes; del cinismo de los constructores; de los "tour" del presidente Flores; de los reclamos o clamores de la gente; de las denuncias de los ecologistas; del dolor de las personas.

Lo que más me ha impactado, en primer lugar, es el poco respeto o aprecio que el gobierno tiene a la vida humana. No entiendo cómo habiendo detectado a una persona con vida en medio de los cscombros, no se dispuso de lodos los medios necesarios para rescatarla con la prontitud debida. Treinta horas fueron necesarias para que un grupo de voluntarios, armados de rudimentarios instrumentos, de entusiasmo, solidaridad y amor por la vida, rescataran al joven Sergio, pero tal parece que fue demasiado larde. ¿Cuántas personas más pudieron haber sido rescaladas con vida, si contáramos con el personal especializado y los equipos idóneos? ¿Cómo es posible que en un país con enormes riesgos sísmicos y de otra índole, no se cuente con un grupo especializado y bien equipado para llevar a cabo tareas de rescate? Ya que el Ministerio de Defensa cuenta con recursos materiales y personal, el cual no hace mucho, pero se le paga a tiempo completo, ¿por qué no especializar a unos cuantos batallones en tareas de rescate? Si durante la guerra se crearon batallones elites especializados para matar a sus hermanos, ipor qué en tiempos de paz no crean batallones de rescate para salvar vidas? ¿Será que para esto no ayuda Estados Unidos? Triste realidad.

En segundo lugar y, en contraste con to anterior, me ha llamado la atención la enorme prencupación no por salvar vidas ni por rescatar aunque fuera los restos mortales de seres humanos para que puedan recibir cristiana sepultura, sino por abrir el paso a la circulación de mercancías. Tal parece que la lógica de los ministros empresarios es solamente: el negocio debe continuar. Cuando en una organización social la vida de las personas no es lo prioritario, y ya no se diga el respeto hacia los muertos, esto es una señal clara e inequi- 


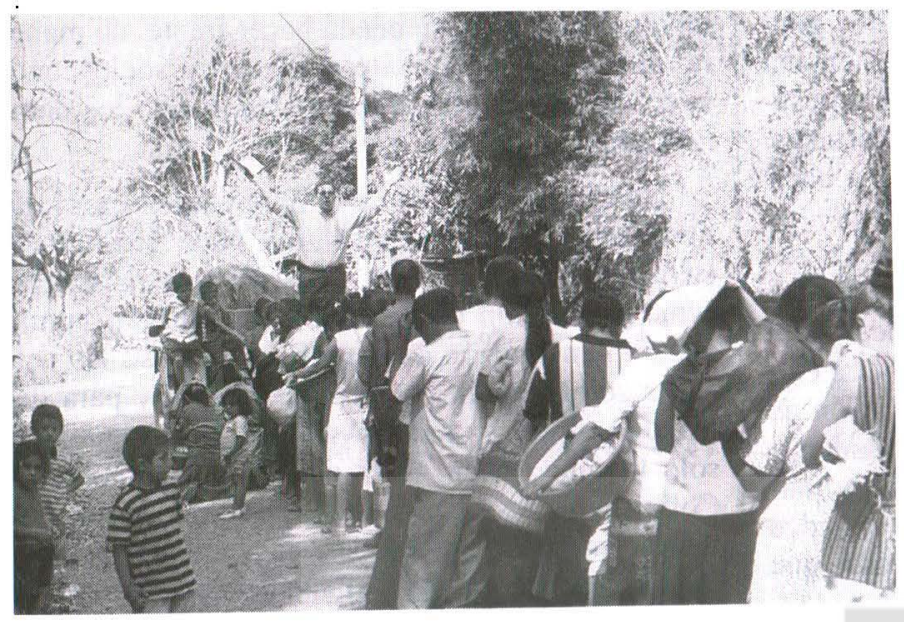

una mínima redistribución de la riqueza. Que sistema más "pura vieja", decía una señora del mercado, pues tiene que ocurrir una tragedia como la sufrida por nuestro pueblo pobre, para que se les caigan unas cuantas migajas a los ri$\cos$ y poderosos. Y esto, mientras se ocupa un lugar en los noticieros internacionales, mientras seamos noticia, porque después, muchos de los ofrecimientos del momento sc quedan en puras promesas. Diferente es la solidaridad popular que se vive y se practica, día tras día, sin esperar nada a cambio; la que se hace en silencio, sin necesidad de anunciarse en los medios masivos de comunicación, como lo

voca de que estamos peor de lo que nos imaginamos. Esto ya fue evidente durante la guerra, pero cualquiera pudo haber pensado que era por la guerra. Pero no. Seguimos igual en tiempos de paz. Nos hemos materializado tanto, que decimos esto en el peor sentido que esta palabra pueda tener y con toda la energía que se pueda decir. Hay valores humanos que no pueden ni deben perderse, y el respeto a la vida siempre me ha parecido el fundamental. Por eso soy pacifista, por eso no apoyo la pena de muerte, por eso condeno a los asesinos, por eso no estoy de acuerdo con las guerras, sean del tipo que sean. Estoy por la vida, sin importar de quien sea. Hasta donde me lo permiten mis conocimiento, creo que en todas las civilizaciones anteriores, con mayor o menor énfasis, el respeto a la vida ha sido una constante. ¿Qué ha pasado con esta civilización del capital que da prioridad a lo material sobre todas las cosas, inclusive, sobre la vida?

En tercer lugar, resulta sorprendente cómo se busca evadir responsabilidades ante la desgracia de La Colina, lo cual es indignante porque al no reconocer tales responsabilidades, se están asegurando, en un futuro más próximo que lejano, desgracias scmejantes o mayores para los habitantes de las colonias ubicadas en las faldas de colinas, cerros o montañas. Los deslaves no sólo ocurren por causas telúricas, recordemos la desgracia de Montebello.

Ciertamente que un evento como el del 13 de enero es terrible, doloroso y miserable, porque se ensañó en los más pobres de los pobres. Pero para los damnificados del sistema es la única oportunidad que se les presenta para que haya, aunque sea, han hecho algunas empresas y muchos embajadores. Ésa es la solidaridad de los pobres, no es una solidaridad de clase, como la de los empresarios, sino una solidaridad humana, natural, que ni siquiera el capitalismo, con toda su carga de individualismo y materialismo, ha logrado destruir. Y es que los pobres son solidarios día tras día, de lo contrario perecerían muchos más.

Por otra parte, el editorialista de El País, España, decía, tres días después del terremoto en El Salvador:

Pero el benéfico ramalazo de la emoción urgente - aviones de socorro, donativos, etc.- no pucde hacernos olvidar que desastres como este recuerdan una vez más la hipocresía institucional que rige las relaciones entre países ricos y pobres. Por ceñirnos a nuestro ámbito, en Europa sólo Dinamarca, Holanda y Suecia cumplen el objetivo fijado hace treinta años por Naciones Unidas de que el mundo desarrollado dedicara cl 0.7 por ciento de sus recursos a las naciones subdesarrolladas. España, con un vergonzoso 0.23 por ciento del producto interno bruto según las últimas estadisticas, está a la cola de la Unión Europea. El imperio por antonomasia, Estados Unidos, después de una década de riqueza sin parangón, dedica al mismo capítulo menos del 0.10 por ciento. Sobran las palabras.

Desdichadamente, Estados Unidos es generoso cuando se trata de actividades necrófagas, como las guerras; por algo es la mayor civilización del capital. Esa cosa muerta que se alimenta sin piedad de los vivos. 
Los desastres naturales, al igual que las gueras, son procesos masivos de destrucción humana y material, donde los pobres sufren y los empresarios reproducen en escala ampliada sus fortunas. Quizá por eso la cementera estuvo presta a decir presente por la patria, mientras hacía cálculos de las ganancias futuras. Sus directores pensaban, seguramente, en los enormes pedidos de cemento que vendrán para reconstruir miles de viviendas destruidas por el terremoto y, además, en todas las empresas dedicadas a la construcción y fabricación de distintos bienes destruidos que deberán reponerse. Mientras unos sufren sus pérdidas humanas y materiales, otros, en cambio, sonríen entusiasmados con la esperada reactivación de la economía que se traducirá en fabulosas ganancias.

Entiendo la preocupación solidaria por los damnificados del terremoto pero, ¿será preciso que ocurran tales desastres para que nos demos cuenta de la miseria en que vive nuestra gente, los damnificados del sistema, esos que todos los días del año no tienen casa, ni medicinas, ni educación, ni agua potable, ni energía eléctrica y, en muchos casos, ni siquiera alimentos y que aprovechando las ayudas se inscriben como damnificados, $y$ a quienes el editorialista de un matutino llama aprovechados? ¿Será que sólo somos Ilamaradas de tusa? ¿Impulsivos, sensibleros y hasta hipócrilas?

Si se pagaran mejores salarios habría menos pobres y si se generaran nuevos puestos de trabajo habría menos miseria. Si se dotara de activos a los pobres, de manera que ellos mismos generaran los ingresos necesarios para satisfacer sus necesidades, la misericordia y la caridad, el asistencialismo y el paternalismo podrían reducirse y verse en casos excepcionales. Pero el gran problema es que cuando tenemos un desastre, como el recientemente ocurrido, la miseria se profundiza y se incrementa el número de pobres. $Y$ por más optimista que quiera ser, no veo cómo, sin renunciar a la lógica del sistema, se pueda hacer frente, de manera efectiva y permanente, al desastre socioeconómico de la mayoría de los salvadoreños: los damnificados del sistema.

Nuestro sistema, el de la libre empresa y el del libre comercio internacional, que hace ricos a unos cuantos empresarios y a unos cuantos países, no actúa en función del ser humano como tal humano, sino en función del beneficio. Por eso las personas sólo cuentan como demandantes y para demandar es preciso tener. Así, parecen ser humanos sólo los que tienen. Si la persona atrapada en La Colina hubiese sido un oligarca, esto es, alguien que tuviese muchas propiedades, seguramente hubiese salido bien librado. Pero si apenas tiene para vivir, poco importa que sea artista, intelectual, filósofo o humanista. Apenas eres un pobre consumidor, sin mayor capacidad de demanda y apenas cuentas dentro de la sociedad. Tu vida no vale nada.

Es terrible y cuesta aceplar que esta es la sociedad en la que vivimos y por eso el padre Sobrino dice, seguramente, que: "Vivir en este país es siempre una carga muy dura de llevar". Para agregar a continuación: "Vivir es, pues, una carga, pero no lo es para todos por igual". $Y$ vaya que tiene razón. Si a los empresarios y a los países ricos les duele tanto la carencia de bienes y servicios que ahora enfrenta, de manera exponencial, nuestro pueblo, ¿por qué no hacen nada para beneficiar de manera permanente a los damnificados del sistema que, ciertamente, no difieren mucho de los actuales damnificados por el terremoto? ¿Dónde eslán las cuantiosas donaciones de los ricos más ricos de El Salvador? ¿Cuántas casas donará la cementera? ¿Cuántas CASALCO? ¿Cuántas la ASI? ¿Cuántas la ANEP?

Aquiles Montoya Catedrático del Departamento de Economía de la UCA 